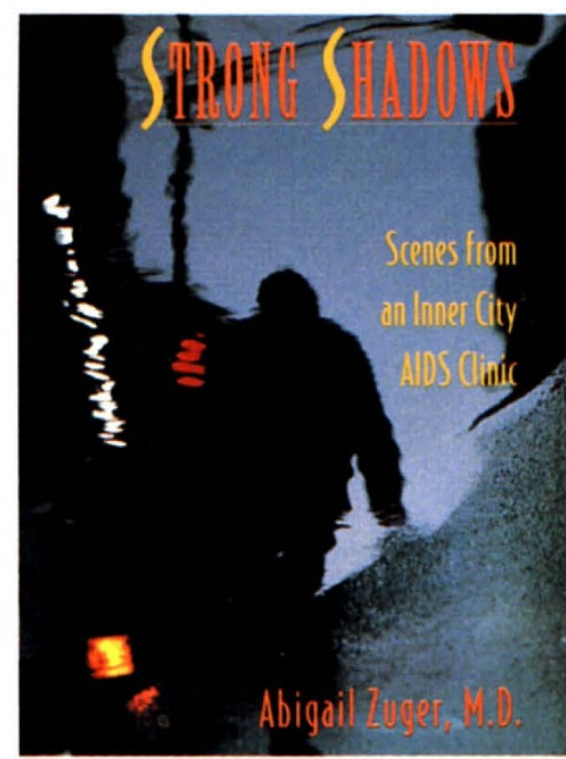

\section{Strong Shadows}

\section{SCENES FROM AN INNER CITY AIDS CLINIC}

\author{
by Abigail Zuger \\ W.H. Freeman and Company \\ New York, New York, $\$ 22.95$ \\ ISBN: 0-7167-2916-4
}

\section{REVIEWED BY ROBERT HEIMER \\ Department of Epidemiology and Public Health Yale University School of Medicine \\ New Haven, Connecticut 06520-8034}

It is through the examination room that Dr Abigail Zuger comes to know her patients in Strong Shadows: Scenes from an Inner City AIDS Clinic. And throughout most of this book, we, too, are in the examination room to discover the broad outlines and the intimacies of the lives of eight patients. The use of the examination room provides a frame both for the reader and Zuger. By keeping us in the room, the strength of each narrative emerges as, piece by piece, we learn how the doctor and the patient are handling the complexities of HIV disease and coping with the finality of AIDS. Medical charts seem to unfold, clinical ambiguities are resolved, patients return with new or the same old problems, and complicated lives are continued. The reality of HIV disease is a constant companion.

This book is, however, as much about health as it is about disease. Zuger describes the struggles of her patients to stay healthy. There are HIV-positive pa- tients like Anita Lewis, almost succeeding in not looking sick despite progressing Pneumocystis pneumonia, and Eddie Rios, more concerned with the doctor's wellbeing than he is with his own, who stand in contrast to our stereotyped visions of AIDS sufferers. They do not waste away; they do fight back. Although they are poorly integrated into the health-care system and often forced to seek out care through emergency rooms, their health, their spirits and their control over their lives wax and wane. Only occasionally, as in the case of Cynthia Wilson, does Zuger exit the examination room to look at the enormous problems that threaten the health of all people, HIV-positive and HIV-negative alike, who live in poverty in the inner city. But the book is much more concerned with descriptions of the swings of health and HIV disease. These descriptions, rendered in clear, jargonfree prose, give the book enormous power to help us understand the several levels on which people with AIDS must simultaneously fight to stay alive. Zuger structures her book to reinforce this understanding. She compresses the conclusions of all the cases into a three page epilogue that after several hundred pages of narrative allows us to remember the individuals while recognizing the all-too-common outcome of HIV disease.

Zuger is a gifted narrator, and she includes much that is uncommon in describing the disease course of the patients she encounters in her examination room. She relates with mixed anger and compassion the case of Shannon Gallagher, an AIDS patient for one year in spite of being HIV-negative, who needed to be connected to the population of AIDS sufferers. In one section, Zuger focuses on one of two HIV-positive patients in a family, describing the complexities of the husband's illness, the wife's struggles to help him help himself to adequate medical coverage, and his persistent dermatitis. But then she ends the section concentrating, $\mathrm{O}^{\prime}$ Henry-like, on the rapid deterioration of his wife. Zuger permits us to see that HIV disease has altered the course of everyone it touches. And while only hinting at it, it is clear that she has been altered as much as any of her patients.

Keeping herself in the examination room also appears to be a necessity for Zuger. Her sanity and strength in the face of the hardest blows of the AIDS epidemic come from remembering where her strength resides. In her examination room, she can diagnose and often successfully treat the range of opportunistic infections and systemic deteriorations that result from HIV infection. Implicit in the framing is that she does not have much of a chance beyond that room. Her patients come from environments that Zuger convinces us, often with just a few sharp, spare sentences, are deleterious to their treatment. As in old novels or modern day Kikwit, Zaire, where the Ebola virus began, admission to the hospital is a brush with death. Other medical specialists (and even some of her fellow infectious disease practitioners) treat HIV-positive patients with contempt, like the pulmonary specialists who won't permit HIV-positive patients to be tested on their pulmonary function machinery. Zuger reminds us of the limitations of AIDS therapies and the careful way in which they need to be applied and combined and of how easy it is to overlook the obvious. On the other hand, she also relates incidents in which the obvious solution was not correct, without making it look as if she has accomplished anything miraculous. What comes across most clearly in these narratives is that she cares for her patients. And it is clear that she can care for them best in her examination room.

The strong narrative sense that keeps the focus on the individual patient had, for me, one unintended consequence. I kept looking for some deeper level of meaning. I guess this response is unavoidable given the current role AIDS plays with our society. Susan Sontag, in AIDS and Its Metaphors, argues that AIDS has become more than just a diagnosis that brings almost certain suffering and death. It is almost unavoidable that AIDS is never just itself, since other meanings become attached which add extra weight to the diagnosis of AIDS. The extra weight can result in discrimination or rejection or it can serve as a source of strength. The patients we briefly encounter in Zuger's examination room are animated by these other meanings of AIDS, but the descriptions of the interactions of the patient and the physician are first and finally about HIV disease. The ultimate strength of Strong Shadows is, therefore, that within the covers of the book, as within Dr Zuger's examination room, AIDS is just itself and her patients respond within the limits of the care that she can provide. 